don't have a medical degree?" he wrote, noting that he can recall only a handful of times when customers experienced blistering or scarring.

"Some people cannot afford the prices that many doctors would charge and, as a result, try to conduct their own procedures to remove their unwanted tattoos (cutting themselves, sanding their tattoos, applying dangerous chemicals to the skin - I have seen it all). These techniques carry far more risk than using a laser."

Of course, if the many failed attempts to regulate the procedure in Alberta are any indication, perhaps Miller and others in the industry have little to worry about. Over the past decade, the College of Physicians and Surgeons of Alberta has requested - multiple times, without success - that the government add the use of lasers to the province's list of restricted health activities. If it were on the list, laser tattoo removal could only be performed by a regulated health practitioner.

"You are applying energy to tissue," said Dr. Trevor Theman, the college's registrar. "There is risk of a problem if you don't know what you are doing."

Regulating tattoo removal is difficult, though, said Theman. If only physicians were doing it, the college could regulate the practice. And the government regards the procedure as cosmetic, so it doesn't fall under the health ministry's purview. Still, the college views tattoo removal as potentially harmful if performed by unskilled practitioners and sees no reason to change its position.

"It should be regulated and there should be some oversight," said Theman. "There should be a mechanism by which members of the public can complain and raise concerns." — Roger Collier, CMAJ

CMAJ 2015. DOI:10.1503/cmaj.109-5026

\title{
TB: fighting a forgotten disease in Canada
}

$\mathrm{N}$ oah Papatsie was working as a television producer in Iqaluit when a minor mishap changed his life.

"My coworker put a light on and it popped right in front of me," he recalls. "Right there, I lost sight in my right eye."

A local doctor said that incident couldn't cause blindness, and he waited six months to get a second opinion from specialists in Ottawa. Papatsie was shocked to learn he had tuberculosis (TB). The infectious disease usually attacks the lungs but can also affect other organs.

There was no way of knowing how long Papatsie had been contagious. And because Nunavut outsources all TB testing to nearby provinces, it took agonizing weeks for those back home to find out if they too were infected.

Papatsie is now TB-free, but totally blind. If it had been diagnosed earlier, he says, "I would still see today."

Canada has about 1600 new TB cases each year - relatively few compared to other countries, but it's precisely because TB is so rare that we're ill-equipped to quickly diagnose and ultimately to eradicate the disease.

"Someone can be coughing for six weeks and we often don't think of TB," says Dr. Maureen Mayhew, a public health physician at the $\mathrm{BC}$ Centre for Disease Control (BCCDC).

Part of the problem is that cases have become concentrated in marginalized populations. About $75 \%$ involve immigrants and 20\% involve Aborigi-

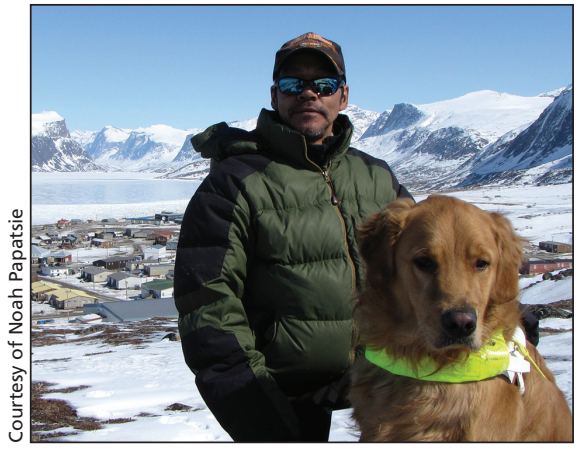

For Noah Papatsie and other Northerners, tuberculosis is a fact of life.

nal people, typically in the North where overcrowding, high smoking rates and other risk factors prevail.

Both groups present unique challenges and Canada's failure to address those is partly why the decline in TB has slowed in recent years, says Mayhew. That's changing now.

$\mathrm{BC}$ is taking aim at latent $\mathrm{TB}$ cases. About 5\%-10\% of these dormant cases will later become active TB, although individual risk is tough to predict. Most immigrants undergo screening for active TB before entering Canada, but that only detects about $4.5 \%$ of cases. Others with latent TB go undetected and are difficult to capture for a second screening, because from their perspective they're clear, says Mayhew.

The BCCDC recently released videos in six languages to help health workers explain latent TB to patients. Work is also underway to screen patients at higher risk, including those with HIV.
Aboriginal and Northern communities face different challenges to TB control. In Nunavut, where TB rates rival those in high-incidence countries like Bangladesh, it can take up to a month for test results to arrive from a lab outside the territory.

Potentially infectious patients often return to their communities while they await diagnosis, says Dr. Gonzalo Alvarez, a scientist and staff respirologist at the Ottawa Hospital. In addition, physicians in the south may not readily recognize the disease, says Dr. Madhukar Pai, associate director of the McGill International TB Centre in Montréal.

In March, Nunavut announced \$1.5 million for a slate of new TB initiatives, including an awareness campaign, a community educator, term nurses for areas with new active cases and a laboratory technician to run a new DNA testing unit in Iqaluit.

The Xpert MTB/RIF unit can identify the TB bacteria's genetic code in fewer than two days with $85 \%$ accuracy. Operating the WHO-endorsed unit in Iqaluit's hospital cut the average wait for diagnosis by up to 37 days.

"These patients are usually feeling terrible - they have weight loss, night sweats, fever and chronic cough," says Alvarez. "Being able to start treatment the next day instead of next month will make a world of difference." - Lauren Vogel, CMAJ

CMAJ 2015. DOI:10.1503/cmaj.109-5035 